\title{
New developments in the treatment of primary insomnia in elderly patients: focus on prolonged-release melatonin
}

REVIEW

\section{Daniel P Cardinali \\ María F Vidal \\ Daniel E Vigo}

Department of Teaching and Research, Faculty of Medical Sciences, Pontificia Universidad Católica Argentina, Buenos Aires, Argentina
Correspondence: Daniel P Cardinali Departamento de Docencia e Investigación, Facultad de Ciencias Médicas, Pontificia Universidad Católica Argentina, Av Alicia Moreau de Justo I500, 40 piso, I 107 Buenos Aires, Argentina

$\mathrm{Tel}+54$ I। 43490200 ext 23 I0

Fax +54 I| 43380720

Email danielcardinali@uca.edu.ar
This article was published in the following Dove Press journal:

ChronoPhysiology and Therapy

II October 2012

Number of times this article has been viewed
Abstract: A temporal relationship between the nocturnal rise in melatonin secretion and the increase in sleep propensity at the beginning of the night, coupled with the sleep-promoting effects of exogenous melatonin, indicate that melatonin is involved in the regulation of sleep. This action is attributed to the $\mathrm{MT}_{1}$ and $\mathrm{MT}_{2}$ melatonin receptors present in the hypothalamic suprachiasmatic nucleus and other brain areas. The sleep-promoting actions of melatonin, which are demonstrable in healthy humans, have been found to be useful in subjects suffering from circadian rhythm sleep disorders and in elderly patients, who had low nocturnal melatonin production and secretion. The effectiveness of melatonin in treating sleep disturbances in these patients is relevant because the sleep-promoting compounds that are usually prescribed, such as benzodiazepines and related drugs, have many adverse effects, such as next-day hangover, dependence, and impairment of memory. Melatonin has been used for improving sleep in patients with insomnia mainly because it does not cause any hangover or show any addictive potential. However, there is a lack of consistency concerning its therapeutic value (partly because of its short half-life and the small quantities of melatonin used). Thus, attention has been focused either on the development of more potent melatonin analogs with prolonged effects or on the design of slow-release melatonin preparations. A prolonged-release preparation of melatonin $2 \mathrm{mg}$ (Circadin ${ }^{\circledR}$ ) has been approved for the treatment of primary insomnia in patients aged $\geq 55$ years in the European Union. This prolonged-release preparation of melatonin had no effect on psychomotor functions, memory recall, or driving skills during the night or the next morning relative to placebo, and was associated with significantly less impairment on many of these tasks relative to zolpidem alone or in combination with prolonged-release melatonin. In 3-week and 6-month randomized, double-blind, clinical trials in patients with primary insomnia aged $\geq 55$ years, prolonged-release melatonin was associated with improvements relative to placebo in many sleep and daytime parameters, including sleep quality and latency, morning alertness, and quality of life. Prolonged-release melatonin was very well tolerated in clinical trials in older patients, with a tolerability profile similar to that of placebo. Short-term or longerterm treatment with prolonged-release melatonin was not associated with dependence, tolerance, rebound insomnia, or withdrawal symptoms.

Keywords: insomnia, melatonin, Circadin $^{\circledR}$, clinical trials

\section{Introduction}

Insomnia is a common disorder, the definition of which is not clearly settled as yet. ${ }^{1}$ It is a condition of unsatisfactory sleep, either in terms of sleep onset, sleep maintenance, or early waking. It is also a disorder that affects daytime and subjective well-being, skills, and performance. Like pain, insomnia is a subjective disorder amenable to diagnosis through clinical observations rather than through objective measurements. ${ }^{1}$ 
Insomnia may begin with a specific problem, for example, a stressful life event, and in some people, the acute insomnia episode progresses to a chronic state. ${ }^{2}$ Factors involved in the persistence of insomnia include iteration of precipitating stress, anxiety about sleep, maladaptive sleep habits, or an intrinsic vulnerability of the neural mechanism regulating sleep. Insomnia is often comorbid with other psychiatric disorders, especially anxiety and depression, or with physical illness, such as cancer or arthritis. ${ }^{2}$

Epidemiological surveys indicate that up to $40 \%$ of individuals over 65 years of age are dissatisfied with their sleep or report trouble in initiating and maintaining sleep, and that $12 \%-25 \%$ complain of persistent insomnia. ${ }^{3-5}$ This leads to increased use of hypnotics by older adults, which is a cause for concern. ${ }^{2,6} \mathrm{Up}$ to $30 \%-40 \%$ of seniors use a sedative-hypnotic benzodiazepine or related medication, and frequently show side effects from hypnotics due to both increased nervous system sensitivity and decreased serum albumin (that binds the drugs). Thus, older patients respond to drugs differently and less predictably than their younger counterparts. ${ }^{7,8}$

In aging individuals, a combination of altered sleep and sleep pathologies increases the risk of drug-induced insomnia or excessive diurnal somnolence. ${ }^{3-5}$ Pharmacokinetic and pharmacodynamic changes due to progressive aging and comorbid medical problems can make treatment more difficult and potentially risky. ${ }^{9}$ Many older adult patients are treated for longer periods or with higher dosages of hypnotic drugs than are recommended, generally with a lack of individual dosage titration.

Several studies have shown the importance of melatonin both for initiation and maintenance of sleep, and this has been reviewed elsewhere. ${ }^{10-12}$ In human beings, the onset of melatonin secretion coincides with the timing of the increase in propensity for nocturnal sleep. ${ }^{13}$ Measurements of melatonin in body fluids in elderly subjects have demonstrated convincingly an age-related impairment of nocturnal pineal melatonin synthesis. ${ }^{14-16}$ Because melatonin exhibits both hypnotic and chronobiotic properties, it has been used for treatment of age-related insomnia as well as of other primary and secondary insomnia. Melatonin has also been used successfully for treatment of sleep problems related to perturbations of the circadian time-keeping system, like those caused by jet-lag, shift work disorder, or delayed sleep phase syndrome. ${ }^{17-19}$

Because melatonin has a short half-life, its efficacy in promoting and maintaining sleep has not been uniform in the studies undertaken so far. Thus, the need arose for the development of prolonged-release preparations of melatonin or of melatonin agonists with a longer duration of action on sleep regulatory structures in the brain. ${ }^{20}$ A prolonged-release form of melatonin known as Circadin ${ }^{\circledR}$, a $2 \mathrm{mg}$ preparation developed by Neurim Pharmaceuticals, Tel Aviv, Israel, was approved by the European Medicines Agency in 2007 for the treatment of insomnia in patients $\geq 55$ years of age. ${ }^{10}$

This review focuses on the data published concerning this prolonged-release melatonin preparation in the context of recent developments on melatonin physiology. The relevant medical literature was identified by searching the Medline and Embase databases, bibliographies from the published literature, and clinical trial registries and databases. The searches were last updated on August 5, 2012.

\section{Benzodiazepines and related drugs in insomnia}

Benzodiazepines exert sedative actions through activation of $\mathrm{BZ}_{1}$ and $\mathrm{BZ}_{2}$ receptor subtypes of the gamma-aminobutyric acid $(\mathrm{GABA})_{\mathrm{A}}$ complex, with activation of $\mathrm{BZ}_{1}$ accounting for their specific hypnosedative, anxiolytic, and anticonvulsant activities. ${ }^{21}$ The $\alpha_{1}$-subunit of the GABA A receptor mediates the sedative and anxiolytic effects of benzodiazepines. ${ }^{22}$ The efficacy of benzodiazepines in treating insomnia was supported by several meta-analyses, with one including 22 studies, which indicated that benzodiazepines increase total sleep time, improve total sleep quality, and reduce sleep onset latency. ${ }^{23}$ However, benzodiazepines also have significant adverse effects, including cognitive and psychomotor impairment, anterograde amnesia, next-day hangover, and rebound insomnia. Because of their adverse effects, use of benzodiazepines for the treatment of insomnia in the elderly has become controversial. ${ }^{2,12}$

Nonbenzodiazepine drugs like zolpidem, zaleplon, and zopiclone all have high affinity and selectivity for the $\alpha_{1}$-subunit of the $\mathrm{GABA}_{\mathrm{A}}$ receptor complex. ${ }^{24}$ Zolpidem improves sleep maintenance shortly after administration, but the effect disappears at a later stage. ${ }^{1,25,26}$ It may cause adverse effects like daytime drowsiness, dizziness, headache, and nausea. Zaleplon, a pyrazolopyramidine derivative, is effective for decreasing sleep onset latency and improving sleep quality, ${ }^{27}$ and because of its efficacy and safety, it is advocated for treating subjects with sleep initiation difficulties. ${ }^{28}$ Zopiclone and its active stereoisomer, eszopiclone, have both been shown to be effective and safe in patients with primary insomnia. ${ }^{24,29}$ In general, nonbenzodiazepine sedative hypnotics, although effective in 
reducing sleep onset latency, are only moderately effective in increasing sleep efficiency and total sleep time. ${ }^{30}$

Indeed, an ideal hypnotic drug should not only decrease sleep onset latency but should also increase total sleep time and sleep efficiency. ${ }^{1}$ In addition, the ideal hypnotic should not produce undesired effects, such as impairment of memory, cognition, psychomotor retardation, and next-day hangover effects, or have the potentiality of abuse.

\section{Melatonin and insomnia}

The sleep-promoting activity of melatonin in humans has been known for years. ${ }^{31,32}$ A number of studies have pointed to a beneficial effect of melatonin in a wide variety of sleep disorders. ${ }^{10,11,33,34}$ However, controversy continues to surround claims of the therapeutic potential of melatonin. A meta-analysis of the effects of melatonin on sleep disturbances in all age groups (including young adults with presumably normal melatonin levels) failed to document significant and clinically meaningful effects of exogenous melatonin on sleep quality, efficiency, and latency. ${ }^{35}$ However, another meta-analysis involving 17 controlled studies in older subjects has shown that melatonin was effective in increasing sleep efficiency and reducing sleep onset latency. ${ }^{36} \mathrm{~A}$ recent consensus from the British Association for Psychopharmacology on evidencebased treatment of insomnia, parasomnia, and circadian rhythm sleep disorders concluded that melatonin is the first choice treatment when a hypnotic is indicated in patients over 55 years. $^{1}$

Studies carried out using $0.3-1 \mathrm{mg}$ doses of melatonin, that produced physiological melatonin levels in the circulation, have shown that melatonin reduced sleep onset latency and increased sleep efficiency when administered to healthy human subjects in the evening. ${ }^{37,38}$ However, in most studies, higher amounts of melatonin (2-6 mg) need to be given to obtain effects. Brain imaging studies in awake subjects have revealed that melatonin modulates the brain activity pattern to one resembling that of actual sleep. ${ }^{39}$

\section{Basic physiology of melatonin}

Although melatonin is synthesized in a wide variety of tissues, circulating melatonin comes almost entirely from the pineal gland. ${ }^{40}$ Synthesis of melatonin in the pineal gland is regulated by the master clock in the hypothalamic suprachiasmatic nucleus; under certain circumstances, like exposure to light at night, this clock signal can be overridden downstream from the clock by visual inputs which suppress melatonin synthesis.

\section{Melatonin metabolism}

Because melatonin is a lipophilic substance, once it is synthesized in the pineal gland, it diffuses readily into the bloodstream, where it is bound to albumin. ${ }^{41}$ Melatonin rapidly disappears from the blood, with a half-life that is biexponential, with a first distribution half-life of 2 minutes and a second of 20 minutes. ${ }^{42}$

Circulating melatonin is metabolized mainly in the liver, which clears $92 \%-97 \%$ of circulating melatonin in a single pass. ${ }^{43}$ Melatonin is first hydroxylated in the C6 position by cytochrome P450 (CYP) mono-oxygenases (isoenzymes CYP1A2, CYP1A1, and, to a lesser extent, CYP1B1), and thereafter is conjugated with sulfate to be excreted as 6-sulfatoxymelatonin, with glucuronide conjugation being extremely limited. ${ }^{42}$ CYP2C19 and, at lower rates, CYP1A2, also demethylate melatonin to its precursor, $N$-acetylserotonin. ${ }^{44}$

Tissues of neural origin, including the pineal gland and retina, contain melatonin-deacetylating enzymes, which are either specific melatonin deacetylases or less specific aryl acylamidases. ${ }^{40}$ Melatonin metabolism in the brain involves oxidative pyrrole ring cleavage. The primary cleavage product is $N^{1}$-acetyl- $N^{2}$-formyl-5-methoxykynuramine (AFMK), which is deformylated, either by arylamine formamidase or hemoperoxidase, to $N^{1}$-acetyl-5-methoxykynuramine (AMK). Some estimations indicate that pyrrole ring cleavage contributes to about one third of the total catabolism of melatonin, but the percentage may be even higher in certain tissues. Other oxidative catabolites are cyclic 3-hydroxymelatonin, which can also be metabolized to AFMK, and a 2-hydroxylated analog, which does not cyclize but turns into an indolinone. ${ }^{40}$ Additional hydroxylated or nitrosated metabolites have been detected, but they appear to be present in minor quantities only.

AFMK and $N^{1}$-acetyl-5-methoxykynuramine form metabolites by interaction with reactive oxygen and nitrogen species. AFMK is produced by numerous nonenzymatic and enzymatic mechanisms, ${ }^{40}$ and its formation by myeloperoxidase appears to be important in quantitative terms. ${ }^{45}$ Antioxidative protection, safeguarding of mitochondrial electron flux and, in particular, neuroprotection, have been demonstrated in many experimental systems to be mediated by melatonin and its endogenous metabolites.

\section{Melatonin receptors}

Binding sites for melatonin were initially identified in a wide variety of central and peripheral tissues using ${ }^{3} \mathrm{H}$-melatonin ${ }^{46,47}$ and later $2-\mathrm{I}^{125}$-iodomelatonin. ${ }^{48}$ Molecular cloning of the 
first high affinity membrane melatonin receptor $\left(\mathrm{MT}_{1}\right)$ was accomplished using a cDNA library constructed from a dermal cell line of melanophores, the first tissue in which the action of melatonin had been demonstrated. ${ }^{49}$ This initial finding led to the discovery that that there are at least two $\mathrm{G}_{\mathrm{i}}$ protein-coupled membrane melatonin receptors in humans. The second receptor $\left(\mathrm{MT}_{2}\right)^{50}$ is $60 \%$ identical in its amino acid sequence to the $\mathrm{MT}_{1}$ receptor. Yet a third receptor, now called GPR50, shares $45 \%$ of the amino acid sequence with $\mathrm{MT}_{1}$ and $\mathrm{MT}_{2}$, but does not bind melatonin. ${ }^{51}$

In the mammalian brain, $\mathrm{MT}_{1}$ and $\mathrm{MT}_{2}$ receptors have been reported in the suprachiasmatic nucleus, prefrontal cortex, cerebellar cortex, hippocampus, basal ganglia, substantia nigra, ventral tegmental area, nucleus accumbens, retinal horizontal, amacrine, ganglion cells, and the choroid plexus, and have been discussed elsewhere. ${ }^{52}$ The $\mathrm{MT}_{1}$ receptor is highly expressed in the human suprachiasmatic nucleus ${ }^{53}$ and mainly in vasopressinergic neurons, ${ }^{54}$ a finding that could be critical, given that the release of vasopressin is one of the important constituents of circadian output from the suprachiasmatic nucleus.

$\mathrm{MT}_{2}$ was not detected in an earlier investigation of the human suprachiasmatic nucleus. ${ }^{53}$ This receptor subtype is expressed in the suprachiasmatic nucleus of many mammals and, where present, is particularly important for circadian phase shifting. ${ }^{55,56}$ Exclusion of purely technical reasons for lack of detection of the $\mathrm{MT}_{2}$ receptor in the human suprachiasmatic nucleus (eg, a very low level of expression) is crucial for the design of new melatonergic drugs in therapy. Indeed, circadian clock reset does occur in humans after administering melatonin, ${ }^{57,58}$ and to disclose whether these changes are induced by exclusive $\mathrm{MT}_{1}$ signaling is of the utmost importance. Circadian phase shifting by melatonin is possible in other species in which $\mathrm{MT}_{2}$ receptors have been lost in the course of evolution. ${ }^{59}$

The binding of melatonin to transcription factors of the retinoic acid receptor superfamily, including $\mathrm{ROR} \alpha$ isoforms a, b, and d (formerly called RZR $\alpha$ ), and the product of another gene, ROR $\beta$ or RZR $\beta$, are increasingly considered as being physiologically important. ${ }^{40}$ Some of these transcription factors interact with circadian core oscillators, thereby influencing phasing, resetting, and period lengths of circadian rhythms. In the mammalian brain, expression of ROR $\alpha$ subforms and ROR $\beta$ is detectable in the suprachiasmatic nucleus and other parts of the hypothalamus, the thalamus, pineal gland, retina, spinal cord, and pars tuberalis. ${ }^{40}$ Remarkably, the ROR $\beta$ signal is highest in areas of highest $\mathrm{MT}_{1}$ receptor density, suggesting the possibility that some sort of cooperation exists between the membrane and nuclear receptors, especially in areas containing circadian oscillators. ROR $\beta$ knockout mice exhibited significant circadian changes, eg, larger phase advance and slower resynchronization than wild-type mice. ${ }^{60}$

$\mathrm{MT}_{1}$-mediated effects in the suprachiasmatic nucleus favor sleep initiation via the hypothalamic sleep switch, a structure characterized by typical on-off responses. This switch is thought to activate either wake-related neuronal downstream pathways or promote the sleep-related ones alternately. ${ }^{61}$ Actions via the sleep switch do not seem to represent the exclusive route of melatonin-induced sleep onset. This is not surprising given that sleep and also sleep initiation are complex phenomena in which various brain areas are involved. The thalamus in particular contributes to the soporific effects of melatonin by promoting spindle formation, a characteristic feature of the transition from stage 2 sleep to deeper sleep stages. ${ }^{62}$ This requires an additional thalamocortical interplay known to occur under these conditions. Moreover, the thalamus and other brain areas feed back to the suprachiasmatic nucleus.

In addition to sleep promotion, $\mathrm{MT}_{1}$ and $\mathrm{MT}_{2}$ receptors appear to be involved in the sedating and antiexcitatory effects of melatonin. This has been mainly studied in relation to anticonvulsant actions, ${ }^{63-68}$ which have been linked to a facilitatory role of melatonin in GABAergic transmission. ${ }^{69}$ The anticonvulsant activity of melatoninergic agents seems to be mediated by $\mathrm{MT}_{1}$ and/or $\mathrm{MT}_{2}$ membrane receptors because similar effects were observed with the $\mathrm{MT}_{1} / \mathrm{MT}_{2}$ agonist, ramelteon. ${ }^{70}$ In mammals, the antiexcitatory actions may also be related to the additional anxiolytic, antihyperalgesic, and antinociceptive effects of melatonergic agents. $^{71-77}$

\section{Clinical pharmacology of prolonged-release melatonin}

Table 1 summarizes the relevant information on the efficacy of prolonged-release melatonin in the improvement of sleep quality in patients with primary insomnia. An initial study concerned its efficacy in 12 outpatients aged 68-93 years with insomnia who were taking benzodiazepines and had a low urinary 6-sulfatoxymelatonin output. ${ }^{78}$ In this randomized, double-blind, placebo-controlled crossover study, prolongedreleased melatonin $2 \mathrm{mg}$ /day increased sleep efficiency and total sleep time and decreased wake after sleep onset, sleep latency, number of awakenings, and the fragmental index as assessed by actigraphy. Another study with a similar design replicated the initial findings. ${ }^{79}$ 
Given that, as mentioned earlier, melatonin and benzodiazepines share some neurochemical (ie, interaction with GABA-mediated mechanisms in the brain ${ }^{69}$ ) and behavioral (eg, a similar day-dependent anxiolytic activity ${ }^{65}$ ) properties, melatonin therapy was postulated as an effective tool to decrease the benzodiazepine dose. As early as 1997, two observations pointed to a possible beneficial effect of melatonin in this respect. We reported an open-label study showing that eight of 13 patients with insomnia either discontinued or reduced their benzodiazepine use by $50 \%-75 \%$ after taking a $3 \mathrm{mg}$ dose of rapid-release melatonin. ${ }^{80}$ Dagan et al published a case report on the efficacy of $1 \mathrm{mg}$ of controlled-release melatonin in ceasing any benzodiazepine use completely in a 43-year-old woman who had suffered from insomnia for the previous 11 years. ${ }^{81}$

In a double-blind, placebo-controlled study followed by a single-blind period in 34 outpatients aged 40-90 years with primary insomnia who took benzodiazepines and had low urinary 6-sulfatoxymelatonin levels, 14 of 18 subjects who had received prolonged-release melatonin, but only four of 16 in the placebo group, discontinued benzodiazepine therapy ${ }^{82}$ (Table 1). An open-label study further supported the efficacy of rapid-release melatonin to decrease benzodiazepine use, ie, 13 of 20 patients with insomnia taking benzodiazepines together with melatonin $3 \mathrm{mg}$ could stop benzodiazepine use, while another four patients decreased their benzodiazepine dose to $25 \%-66 \%$ of initial doses. ${ }^{83}$

These observations were not supported by the results of a placebo-controlled study in 38 long-term benzodiazepine users, $40 \%$ of whom had stopped their benzodiazepine use after one year, both in the intervention group receiving melatonin and in the placebo control group. ${ }^{84}$ It must be noted that, on many occasions, older patients with minor sleep disturbance received anxiolytic benzodiazepines or sedative-hypnotic benzodiazepines in low doses on a longterm basis. To assess the efficacy of melatonin in reducing the use of benzodiazepines at very low doses, we carried out a double-blind, placebo-controlled study of 45 patients randomized to receive either rapid-release melatonin $3 \mathrm{mg}$ or placebo for 6 weeks. ${ }^{85}$ The benzodiazepine was tapered off in two steps and stopped after 4 weeks. Several sleep parameters were assessed and found not to be different in either group. That the patients included in our study were taking benzodiazepines for reasons other than an established sleep disturbance was indicated by the lack of subjective changes in sleep quality after reduction or suppression of the benzodiazepine dose. ${ }^{85}$ However, melatonin was not devoid of activity; it advanced sleep onset and decreased variability of sleep onset time significantly when compared with placebo. ${ }^{85}$

A recent retrospective analysis of a German prescription database identified 512 patients who had initiated treatment with prolonged-release melatonin $2 \mathrm{mg}$ over a 10-month period ${ }^{86}$ Of 112 patients in this group who had previously used benzodiazepines, 31\% discontinued treatment with benzodiazepines 3 months after starting prolonged-release melatonin treatment. The discontinuation rate was higher in patients receiving two or three melatonin prescriptions. ${ }^{86}$ Therefore, prolonged-release melatonin can help to facilitate discontinuation of benzodiazepines in older insomniacs.

The efficacy of prolonged-release melatonin in the treatment of insomnia in older patients is supported by the results of both Phase III and IV trials (Table 1). Two double-blind, placebo-controlled trials including $170^{87}$ and $354^{88}$ outpatients aged $\geq 55$ years with primary insomnia indicated a significant improvement in quality of sleep and morning alertness, and in quality of life as well as shortening of sleep latency after 3 weeks of treatment with prolongedrelease melatonin $2 \mathrm{mg}$ (Table 1). No rebound insomnia or withdrawal effects were seen.

Similar results were reported for a clinically relevant subgroup of 578 patients aged $\geq 55$ years in a randomized, 3-week, double-blind trial, followed by a 26-week, double-blind extension period in which patients were randomized to receive melatonin or placebo, followed by a 2-week, single-blind, placebo withdrawal period. ${ }^{89}$ The primary endpoint in this trial was change from baseline in sleep latency at the end of the initial 3-week treatment period in the predefined subgroups of patients with low endogenous levels of urinary melatonin. In patients aged $\geq 65$ years $(n=281)$, melatonin decreased sleep latency regardless of the extent of 6-sulfatoxymelatonin excretion. The effect of prolonged-release melatonin in patients with low urinary 6-sulfatoxymelatonin levels regardless of age did not differ from placebo. Improvement of sleep and daytime parameters was maintained or enhanced over a 6-month period, with no signs of tolerance. Most adverse events were mild in severity and showed no clinically relevant differences from placebo, including endocrine parameters (prolactin, adrenocorticotropic hormone, thyroid hormones, thyroid-stimulating hormone, luteinizing hormone, folliclestimulating hormone, estradiol, free and total testosterone, and cortisol). ${ }^{89}$

A prospective open-label study in 244 community-dwelling adults with primary insomnia (mean age 55.3 years) who received prolonged-release melatonin $2 \mathrm{mg}$ for 6-12 months was recently published. ${ }^{90}$ Sleep diary, adverse events, 
Table I Relevant clinical studies on prolonged-release melatonin in primary insomnia

\begin{tabular}{|c|c|c|c|c|}
\hline Condition & Type of study & $\mathbf{n}$ & $\begin{array}{l}\text { Daily } \\
\text { melatonin dose }\end{array}$ & Duration of treatment \\
\hline $\begin{array}{l}\text { Primary insomnia outpatients } \\
\text { aged } 76 \pm 8 \text { (68-93) years who } \\
\text { took BZP and had low urinary } \\
\text { 6-sulfatoxymelatonin levels }\end{array}$ & $\begin{array}{l}\text { Randomized, double-blind, } \\
\text { placebo-controlled, } \\
\text { crossover study }\end{array}$ & 12 & $2 \mathrm{mg}$ & $\begin{array}{l}3 \text { weeks with melatonin or placebo, } \\
\text { followed by one-week washout, } \\
\text { and then crossed over for } \\
\text { another } 3 \text { weeks }\end{array}$ \\
\hline $\begin{array}{l}\text { Primary insomnia outpatients } \\
\text { aged } 79 \pm 5.2(68-93) \text { years under } \\
\text { BZP treatment and having low } \\
\text { urinary 6-sulfatoxymelatonin levels }\end{array}$ & $\begin{array}{l}\text { Randomized, double-blind, } \\
\text { placebo-controlled, } \\
\text { crossover study }\end{array}$ & 21 & $2 \mathrm{mg}$ & $\begin{array}{l}3 \text { weeks with melatonin or placebo, } \\
\text { followed by one-week washout, } \\
\text { and then crossed over for another } \\
3 \text { weeks }\end{array}$ \\
\hline $\begin{array}{l}\text { Primary insomnia outpatients } \\
\text { aged } 40-90 \text { years who } \\
\text { took BZP and had low urinary } \\
\text { 6-sulfatoxymelatonin levels }\end{array}$ & $\begin{array}{l}\text { Randomized, double-blind, } \\
\text { placebo-controlled study } \\
\text { followed by a single-blind } \\
\text { period }\end{array}$ & 34 & $2 \mathrm{mg}$ & $\begin{array}{l}\text { Patients received melatonin or placebo for } 6 \text { weeks. } \\
\text { They were encouraged to reduce BZP dose } 50 \% \\
\text { during week 2, 75\% during weeks } 3 \text { and } 4 \text {, and } \\
\text { to discontinue BZP during weeks } 5 \text { and } 6 \text {. Then } \\
\text { melatonin was administered (single-blind) for } \\
6 \text { weeks and attempts to discontinue BZP therapy } \\
\text { were resumed; follow-up reassessment } \\
\text { was performed } 6 \text { months later }\end{array}$ \\
\hline $\begin{array}{l}\text { Primary insomnia outpatients } \\
\text { aged } \geq 55 \text { years }\end{array}$ & $\begin{array}{l}\text { Double-blind, } \\
\text { placebo-controlled trial }\end{array}$ & 170 & $2 \mathrm{mg}$ & 3 weeks \\
\hline $\begin{array}{l}\text { Primary insomnia outpatients } \\
\text { aged } \geq 55 \text { years }\end{array}$ & $\begin{array}{l}\text { Double-blind, } \\
\text { placebo-controlled trial }\end{array}$ & 354 & $2 \mathrm{mg}$ & 3 weeks \\
\hline
\end{tabular}

\section{Healthy volunteers}

aged $\geq 55$ years

Primary insomnia outpatients aged 55-68 years

Primary insomnia outpatients aged 18-80 years
Randomized, double-blind, placebo-controlled, single-dose, four-way crossover study

Double-blind,

Randomized, double-blind, parallel-group, clinical trial placebo-controlled trial

$162 \mathrm{mg}$, zolpidem $10 \mathrm{mg}$, and their combination

$40 \quad 2 \mathrm{mg}$

79। $2 \mathrm{mg}$
Prospective open-label study

$244 \quad 2 \mathrm{mg}$

primary insomnia of mean age 55.3 years
Perimenopausal women with insomnia aged 45-52 years
Open-label, case series II $2 \mathrm{mg}$
Subjects were tested one and 4 hours and next morning after dosing

3 weeks
3 -week double-blind treatment, followed by a 26-week, double-blind, extension period with patients randomized to receive melatonin or placebo, followed by a 2-week, single-blind, placebo withdrawal period

6-12 months
Treated with mirtazapine $15 \mathrm{mg}$ for 2-4 weeks. Melatonin was then added on, and mirtazapine was tapered off for another I-3 months 


\author{
Outcome \\ measures \\ Sleep quality was objectively monitored \\ by wrist actigraphy. \\ Sleep assessed by wrist actigraphy. Urinary \\ 6-sulfatoxymelatonin measurement
}

Sleep diary and recording of BZP use

Quality of sleep and morning alertness assessed by Leeds Sleep Evaluation Questionnaire.

Sleep quality reported on five categorical scales. Presence of rebound insomnia or withdrawal effects Responder rate in Leeds Sleep Evaluation Questionnaire, Pittsburgh Sleep Quality Index global score, Quality of Night and Quality of Day derived from a sleep diary, Clinical Global Improvement scale and quality of life (WHO-5 well being index) Psychomotor functions, memory recall, and driving skills

Polysomnography and EEG spectral analysis. Psychomotor performance assessed by the Leeds Psychomotor Test battery

Sleep diary, Pittsburgh Sleep Quality Index, Quality of Life (World Health Organzaton-5) Clinical Global Impression of Improvement assessment, urinary 6-sulfatoxymelatonin and adverse effects and vital signs

Sleep diary, adverse events, vital signs, laboratory tests, and withdrawal symptoms. Nocturnal urinary 6-sulfatoxymelatonin excretion assessed upon discontinuing treatment

Body weight data. Subjective assessment of sleep quality and well-being (Pittsburgh Sleep Quality Index and Well-Being Index, WHO-5)
Response

Sleep efficiency was greater after melatonin than after placebo

and wake time after sleep onset was shorter. Trend to decrease sleep latency. Total sleep time remained unaffected

Melatonin increased sleep efficiency and total sleep time and decreased wake after sleep onset, sleep latency, number of awakenings and fragmental index

14 of 18 subjects who had received melatonin, but only 4 of 16 in the placebo group, discontinued BZP therapy. Sleep-quality scores were higher in the melatonin group. Six additional subjects in the placebo group discontinued BZP after 6 months of treatment. At the follow-up, 19 of 24 patients who discontinued BZP kept good sleep quality

Significant improvement in quality of sleep and morning alertness. The improvements in quality of sleep and morning alertness were strongly correlated. No rebound insomnia or withdrawal effects were seen

Significant improvements in quality of sleep and morning alertness and in quality of life. Shortening of sleep latency

No impairment of performance after melatonin. Zolpidem impaired psychomotor and driving performance one and 4 hours post-dosing, and early memory recall. Melatonin coadministration exacerbated zolpidem effect

Shorter sleep onset latency as compared to placebo. Significantly better scores in the Critical Flicker Fusion Test. $50 \%$ of patients reported substantial improvement in sleep quality at home. No rebound insomnia or withdrawal effects In patients aged $\geq 65$ years $(n=28 \mathrm{I})$ melatonin decreased sleep latency regardless of 6-sulfatoxymelatonin excretion. Effect in patients with low urinary 6-sulfatoxymelatonin levels regardless of age did not differ from placebo. Improvement of sleep and daytime parameters maintained or enhanced over a 6-month period with no signs of tolerance.

Most adverse events were mild in severity with no clinically relevant differences with placebo, including endocrine parameters Of the 244 patients, 36 dropped out, I 12 completed 6 months of treatment, and 96 completed 12 months of treatment. The mean number of nights reporting sleep quality as "good" or "very good" was significantly higher during treatment. There was no evidence of tolerance and discontinuation was not associated with rebound insomnia or withdrawal symptoms. No suppression of endogenous melatonin production

Significant improvement in sleep quality and well-being during subsequent intake of melatonin alone or together with very low doses of mirtazapine, 5 of 7 women demonstrating weight gain following mirtazapine intake started to reduce weight after melatonin treatment 
Table I (Continued)

\begin{tabular}{|c|c|c|c|c|}
\hline Condition & Type of study & $\mathbf{n}$ & $\begin{array}{l}\text { Daily } \\
\text { melatonin dose }\end{array}$ & Duration of treatment \\
\hline $\begin{array}{l}\text { Type } 2 \text { diabetic patients with } \\
\text { insomnia aged } 46-77 \text { years }\end{array}$ & $\begin{array}{l}\text { Randomized, double-blind, } \\
\text { placebo-controlled, } \\
\text { crossover study }\end{array}$ & 36 & $2 \mathrm{mg}$ & $\begin{array}{l}3 \text { weeks with melatonin or placebo, followed by } \\
\text { one-week washout, and then crossed over for } \\
\text { another } 3 \text { weeks. Extension period of } 5 \text { months } \\
\text { giving melatonin to all patients in an open-label design }\end{array}$ \\
\hline $\begin{array}{l}\text { Healthy volunteers, } \\
\text { aged 55-64 years }\end{array}$ & $\begin{array}{l}\text { Randomized, double-blind, } \\
\text { placebo-controlled, } \\
\text { single-dose, three-way } \\
\text { crossover study }\end{array}$ & 24 & $\begin{array}{l}2 \mathrm{mg} \text {, zolpidem } \\
10 \mathrm{mg} \text { was used } \\
\text { as active control }\end{array}$ & $\begin{array}{l}\text { Subjects were tested } 30 \text { minutes before } \\
\text { and } 1.5 \text { and } 4 \text { hours after dosing }\end{array}$ \\
\hline $\begin{array}{l}\text { Patients classified according } \\
\text { to their use of hypnotic BZP } \\
\text { or BZP-like drugs }\end{array}$ & $\begin{array}{l}\text { Retrospective study from } \\
\text { a longitudinal database }\end{array}$ & 112 & $2 \mathrm{mg}$ & Varied intervals \\
\hline
\end{tabular}

vital signs, laboratory tests, and withdrawal symptoms, as well as nocturnal urinary 6-sulfatoxymelatonin excretion were assessed upon discontinuing treatment. Of the initial 244 patients, 36 dropped out, 112 completed 6 months of treatment, and 96 completed 12 months of treatment. The mean number of nights reporting sleep quality as "good" or "very good" was significantly higher during treatment. There was no evidence of tolerance, and discontinuation was not associated with rebound insomnia or withdrawal symptoms. No suppression of endogenous melatonin production was found. ${ }^{90}$

An objective evaluation of sleep in patients on prolongedrelease melatonin treatment was undertaken using polysomnography in a double-blind, placebo-controlled study including 40 outpatients aged 55-68 years with primary insomnia and receiving treatment for 3 weeks. ${ }^{91}$ Treated patients showed shorter sleep onset latency and better psychomotor performance as assessed in the Critical Flicker Fusion Test of Leeds Psychomotor test battery.

Specific groups of insomnia patients, eg, those with diabetes, seem to benefit from treatment with prolongedrelease melatonin. In a randomized, double-blind, placebocontrolled, crossover study in type 2 diabetic patients with insomnia aged 46-77 years, actigraphy showed that sleep efficiency, wake time after sleep onset, and number of awakenings improved significantly. ${ }^{92}$ Although none of the blood parameters changed after 3 weeks of treatment with melatonin, glycosylated hemoglobin levels decreased after 5 months of treatment. ${ }^{92}$

Indeed, an area of interest in the potential applications of melatonin is the metabolic syndrome. A number of studies have indicated that melatonin has the ability to reduce obesity, type 2 diabetes, and liver steatosis in experimental animals. ${ }^{93}$
Low levels of circulating melatonin occur in patients with type 2 diabetes, ${ }^{94}$ concomitant with upregulation of mRNA expression of the melatonin membrane receptor. ${ }^{95}$ In addition, variants in the gene encoding the melatonin receptor have been associated with fasting blood glucose levels and increased risk of type 2 diabetes. ${ }^{96}$

Other aspects of the metabolic syndrome are also linked to abnormal melatonin secretion. Nocturnal secretion of melatonin was lower in patients with coronary artery disease. ${ }^{97-100}$ Night-time melatonin supplementation reduced nocturnal blood pressure in otherwise untreated hypertensive men, ${ }^{101}$ nondipping women, ${ }^{102}$ patients with nocturnal hypertension, ${ }^{103}$ and adolescents with type 1 diabetes mellitus. ${ }^{104}$ Improvement in the lipid profile after melatonin treatment has also been observed in human studies. ${ }^{105}$ An open-label study of the effect of melatonin in patients with the metabolic syndrome phenotype indicates that melatonin $5 \mathrm{mg}$ /day for 2 months significantly decreased high blood pressure, improved the serum lipid profile, and reduced antioxidative status. ${ }^{106}$

Another group of patients who may benefit from treatment with prolonged-release melatonin is perimenopausal women with insomnia. A group of such patients, aged 45-52 years, was studied in an open-label case series (Table 1). ${ }^{107}$ In 11 perimenopausal women who received $2 \mathrm{mg}$ of prolonged release melatonin together with $15 \mathrm{mg}$ mirtazapine for 2-4 weeks and who were tapered off mirtazapine for another 1-3 months, a significant improvement in sleep quality and well-being during combined mirtazapine and melatonin intake and during subsequent intake of melatonin alone was detected ${ }^{87}$ Five of seven women demonstrating weight gain following treatment with mirtazapine started to lose weight after treatment with melatonin. Further studies are needed 


\begin{tabular}{|c|c|c|}
\hline $\begin{array}{l}\text { Outcome } \\
\text { measures }\end{array}$ & Response & Ref \\
\hline $\begin{array}{l}\text { Sleep monitoring by actigraphy. Measuring of fasting } \\
\text { glucose, fructosamine, insulin, C-peptide, triglyceride, } \\
\text { total cholesterol, high-density and low-density } \\
\text { lipoprotein cholesterol, antioxidants and } \\
\text { glycosylated hemoglobin levels }\end{array}$ & $\begin{array}{l}\text { Sleep efficiency, wake time after sleep onset, and number of } \\
\text { awakenings improved significantly. No significant changes in } \\
\text { blood parameters after } 3 \text { weeks of melatonin treatment. } \\
\text { After } 5 \text { months of treatment, glycosylated hemoglobin } \\
\text { levels decreased }\end{array}$ & 88 \\
\hline $\begin{array}{l}\text { Body sway tested by the area of the } 95 \% \\
\text { confidence ellipse enclosing the center } \\
\text { of pressure (A95) and its path length }\end{array}$ & $\begin{array}{l}\text { No effect of melatonin on A95. It increased path length at } \\
4 \text { hours post-dose in open but not closed eyes condition. } \\
\text { Zolpidem significantly increased the A95 and path length }\end{array}$ & 89 \\
\hline Discontinuation rate of BZP & $\begin{array}{l}31 \% \text { of patients discontinued BZP after melatonin initiation. } \\
\text { The discontinuation rate was higher in patients receiving two } \\
\text { or three melatonin prescriptions }\end{array}$ & 90 \\
\hline
\end{tabular}

Abbreviations: BZP, benzodiazepine; EEG, electroencephalography.

to evaluate gender differences in response to treatment with prolonged-release melatonin for insomnia.

Two studies have been undertaken in healthy volunteers to compare the effect of prolonged-release melatonin with that of zolpidem. In a double-blind, placebo-controlled, single-dose, four-way crossover study, 16 healthy volunteers aged $\geq 55$ years were randomized to prolonged-release melatonin or zolpidem $10 \mathrm{mg}$, or a combination of the two agents. ${ }^{108}$ Subjects were tested at one hour, four hours, and the morning after dosing. Psychomotor functioning, memory recall, and driving skills were assessed. No impairment of performance was detected after melatonin, whereas zolpidem impaired psychomotor and driving performance one and four hours post-dosing as well as early memory recall. Melatonin coadministration potentiated the effect of zolpidem. ${ }^{108}$

In another study, the effects of prolonged-release melatonin and zolpidem on postural stability were assessed in healthy older adults. ${ }^{109}$ Twenty-four volunteers, aged 55-64 years, were randomized in a double-blind, placebocontrolled, single-dose, three-way crossover study. Body sway was tested by the area of the $95 \%$ confidence ellipse enclosing the center of pressure (A95) and its path length. No effect of melatonin on A95 was detected. In contrast, zolpidem significantly increased the A95 and path length, pointing to the possibility of postural disturbance caused by the drug. ${ }^{109}$

One important point to address when using a prolongedrelease formulation of melatonin, eg, Circadin, is how it is related to the phase response curve of methoxyindole. . $^{77,58}$ Presumably significant amounts of melatonin will be present at both the phase advance (early night) and phase delay (early morning) parts of the sensitivity curve. Considering that elderly patients are more often phase advanced, it would be of the utmost importance to assess whether the beneficial effect of melatonin on insomnia depends on a phase-delaying effect on the circadian rhythm (by acting like a small morning dose of melatonin, which has been proposed to delay the circadian rhythm).

\section{Safety and place in therapy}

Prolonged-release melatonin has an excellent safety and tolerability record, showing no difference from placebo. Emergent adverse events, including gastrointestinal, cardiovascular, and body weight changes have been absent. Indeed, melatonin is usually remarkably well tolerated and, in some studies, has been administered to patients in very large doses. Melatonin $10 \mathrm{mg} /$ day decreased interleukin-6 levels in patients with cancer ${ }^{110}$ and $300 \mathrm{mg}$ /day doses for up to 3 years decreased oxidative stress in patients with amyotrophic lateral sclerosis. ${ }^{111}$ In children with muscular dystrophy, melatonin $70 \mathrm{mg} /$ day reduced cytokine levels and lipid peroxidation. ${ }^{12}$ Melatonin doses of $80 \mathrm{mg} /$ hour for 4 hours were given to healthy men with no undesirable effects, other than drowsiness. ${ }^{113}$ There were no side effects in healthy women given melatonin $300 \mathrm{mg}$ /day for 4 months. ${ }^{114}$ A recent randomized, controlled, double-blind clinical trial in 50 patients referred for liver surgery indicates that a single preoperative enteral melatonin dose of $50 \mathrm{mg} / \mathrm{kg}$ was safe and well tolerated. ${ }^{115}$ Another important point to consider when dealing with high amounts of melatonin is that, in addition to its low toxicity, it is a potent multiple mitochondrial protector. ${ }^{116-118}$

The ultimate goal of treatment for insomnia is symptomatic and functional recovery that helps a return to everyday life. However, a large proportion of patients on treatment with benzodiazepines fail to achieve a complete 
and sustained recovery and are left with residual symptoms that make relapse or recurrence more likely, and poorer quality of life a reality. Most treatment guidelines recognize a symptom-free state as the best definition of remission of insomnia, in spite of the fact that functional recovery often lags behind symptomatic improvement. Given the importance of all three dimensions of functioning (emotional, cognitive, and social) in everyday activities such as work, and the impact that daily functioning impaired by insomnia may have on a patient's life, it is clear that more attention should be paid to functioning when assessing the response to treatment. ${ }^{119}$ In this respect, most safety concerns about use of hypnotics do not apply to prolonged-release melatonin, a fact recognized by the British Association for Psychopharmacology consensus statement on the evidence-based treatment of insomnia, parasomnias, and circadian rhythm disorders, that recommended prolonged-release melatonin as a first-line treatment for insomnia in patients aged 55 years and older. ${ }^{1}$

\section{Conclusion}

An important point when dealing with the effects of melatonin on sleep is to understand that they are different from those of the benzodiazepines and related drugs in that they exert a promoting effect on sleep by amplifying day/night differences in alertness and sleep quality, and display a modest sleep-inducing effect, which is quite mild as compared with that seen with the benzodiazepines. Because of their long history on the market and the lack of treatment alternatives for insomnia, the preconception on the part of the consumer is that a sleeping pill should be a strong inducer of sleep, something that the melatonin family of compounds will not accomplish. Therefore, a very important educational goal is to change this view because of the lack of negative effects (eg, addiction, dependence) with the melatonin analogs in comparison with well known complications of benzodiazepines.

It should be also be borne in mind that further studies using melatonin doses of $100 \mathrm{mg} /$ day are needed to clarify the potential implications of the native melatonin compound in humans. From animal studies it is clear that a number of potentially useful effects of melatonin, like those in neurodegenerative disorders or in the metabolic syndrome, require administration of high doses of melatonin to become apparent. ${ }^{96,120}$ If one expects melatonin to be effective in improving health, especially in aged people, it is likely that the low doses of melatonin employed so far will not be very beneficial.

\section{Acknowledgments}

This research was supported by grants from the Agencia Nacional de Promoción Científica y Tecnológica, Argentina (PICT 2007-01045/2010-1465) and the Universidad de Buenos Aires (M048). DPC and DEV are recipients of research career awards from the Argentine Research Council. MFV is a CONICET doctoral fellow.

\section{Disclosure}

The authors report no conflicts of interest in this work.

\section{References}

1. Wilson SJ, Nutt DJ, Alford C, et al. British Association for Psychopharmacology consensus statement on evidence-based treatment of insomnia, parasomnias and circadian rhythm disorders. $J$ Psychopharmacol. 2010;24:1577-1601.

2. Morin CM, Benca R. Chronic insomnia. Lancet. 2012;379: 1129-1141.

3. Neikrug AB, Ancoli-Israel S. Sleep disorders in the older adult a mini-review. Gerontology. 2010;56:181-189.

4. Wolkove N, Elkholy O, Baltzan M, Palayew M. Sleep and aging: 1. Sleep disorders commonly found in older people. CMAJ. 2007;176: 1299-1304.

5. Wolkove N, Elkholy O, Baltzan M, Palayew M. Sleep and aging: 2. Management of sleep disorders in older people. CMAJ. 2007;176: 1449-1454.

6. Fetveit A. Late-life insomnia: a review. Geriatr Gerontol Int. 2009;9: 220-234.

7. Boyle N, Naganathan V, Cumming RG. Medication and falls: risk and optimization. Clin Geriatr Med. 2010;26:583-605.

8. Faught E. Monotherapy in adults and elderly persons. Neurology. 2007;69:S3-S9.

9. Wills P, Claesson CB, Fratiglioni L, Fastbom J, Thorslund M, Winblad B. Drug use by demented and non-demented elderly people. Age Ageing. 1997;26:383-391.

10. Zisapel N. Melatonin and sleep. Open Neuroendocr J. 2010;3:85-95.

11. Pandi-Perumal SR, Srinivasan V, Spence W, Cardinali DP. Role of the melatonin system in the control of sleep: therapeutic implications. CNS Drugs. 2007;121:995-1018.

12. Cardinali DP, Srinivasan V, Brzezinski A, Brown GM. Melatonin and its analogs in insomnia and depression. J Pineal Res. 2012;52:365-375.

13. Lavie P. Melatonin: role in gating nocturnal rise in sleep propensity. J Biol Rhythms. 1997;12:657-665.

14. Haimov I, Laudon M, Zisapel N, et al. Sleep disorders and melatonin rhythms in elderly people. BMJ. 1994;309:167.

15. Hughes RJ, Badia P. Sleep-promoting and hypothermic effects of daytime melatonin administration in humans. Sleep. 1997;20:124-131.

16. Leger D, Laudon M, Zisapel N. Nocturnal 6-sulfatoxymelatonin excretion in insomnia and its relation to the response to melatonin replacement therapy. Am J Med. 2004;116:91-95.

17. Zhdanova IV, Wurtman RJ, Regan MM, Taylor JA, Shi JP, Leclair OU. Melatonin treatment for age-related insomnia. J Clin Endocrinol Metab. 2001;86:4727-4730.

18. Arendt J, Skene DJ, Middleton B, Lockley SW, Deacon S. Efficacy of melatonin treatment in jet lag, shift work, and blindness. J Biol Rhythms. 1997;12:604-617.

19. Srinivasan V, Singh J, Pandi-Perumal SR, Brown GM, Spence DW, Cardinali DP. Jet lag, circadian rhythm sleep disturbances, and depression: the role of melatonin and its analogs. Adv Ther. 2010;27:796-813.

20. Turek FW, Gillette MU. Melatonin, sleep, and circadian rhythms: rationale for development of specific melatonin agonists. Sleep Med. 2004;5:523-532. 
21. Mandrioli R, Mercolini L, Raggi MA. Metabolism of benzodiazepine and non-benzodiazepine anxiolytic-hypnotic drugs: an analytical point of view. Curr Drug Metab. 2010;11:815-829.

22. Sigel E, Luscher BP. A closer look at the high affinity benzodiazepine binding site on GABAA receptors. Curr Top Med Chem. 2011;11: 241-246.

23. Nowell PD, Mazumdar S, Buysse DJ, Dew MA, Reynolds CF III, Kupfer DJ. Benzodiazepines and zolpidem for chronic insomnia: a meta-analysis of treatment efficacy. JAMA. 1997;278:2170-2177.

24. Morin AK, Willett K. The role of eszopiclone in the treatment of insomnia. Adv Ther. 2009;26:500-518.

25. Morin AK. Strategies for treating chronic insomnia. Am J Manag Care. 2006;12:S230-S245.

26. Rosenberg RP. Sleep maintenance insomnia: strengths and weaknesses of current pharmacologic therapies. Ann Clin Psychiatry. 2006;18:49-56.

27. Ancoli-Israel S, Richardson GS, Mangano RM, Jenkins L, Hall P, Jones WS. Long-term use of sedative hypnotics in older patients with insomnia. Sleep Med. 2005;6:107-113.

28. Montplaisir J, Hawa R, Moller H, et al. Zopiclone and zaleplon vs benzodiazepines in the treatment of insomnia: Canadian consensus statement. Hum Psychopharmacol. 2003;18:29-38.

29. Hair PI, McCormack PL, Curran MP. Eszopiclone: a review of its use in the treatment of insomnia. Drugs. 2008;68:1415-1434.

30. Zammit G. Comparative tolerability of newer agents for insomnia. Drug Saf. 2009;32:735-748.

31. Vollrath L, Semm P, Gammel G. Sleep induction by intranasal administration of melatonin. Adv Biosci. 1981;29:327-329.

32. Waldhauser F, Saletu B, Trinchard-Lugan I. Sleep laboratory investigations on hypnotic properties of melatonin. Psychopharmacology (Berl) 1990;100:222-226.

33. Zhdanova IV. Melatonin as a hypnotic: pro. Sleep Med Rev. 2005;9:51-65.

34. Srinivasan V, Pandi-Perumal SR, Trahkt I, et al. Melatonin and melatonergic drugs on sleep: possible mechanisms of action. Int J Neurosci. 2009;119:821-846.

35. Buscemi N, Vandermeer B, Hooton N, et al. Efficacy and safety of exogenous melatonin for secondary sleep disorders and sleep disorders accompanying sleep restriction: meta-analysis. BMJ. 2006;332: 385-393.

36. Brzezinski A, Vangel MG, Wurtman RJ, et al. Effects of exogenous melatonin on sleep: a meta-analysis. Sleep Med Rev. 2005;9:41-50.

37. Dollins AB, Zhdanova IV, Wurtman RJ, Lynch HJ, Deng MH. Effect of inducing nocturnal serum melatonin concentrations in daytime on sleep, mood, body temperature, and performance. Proc Natl Acad Sci U S A. 1994;91:1824-1828.

38. Zhdanova IV, Wurtman RJ, Morabito C, Piotrovska VR, Lynch HJ. Effects of low oral doses of melatonin, given 2-4 hours before habitual bedtime, on sleep in normal young humans. Sleep. 1996;19:423-431.

39. Gorfine T, Assaf Y, Goshen-Gottstein Y, Yeshurun Y, Zisapel N Sleep-anticipating effects of melatonin in the human brain. Neuroimage. 2006;31:410-418

40. Hardeland R, Cardinali DP, Srinivasan V, Spence DW, Brown GM, Pandi-Perumal SR. Melatonin - a pleiotropic, orchestrating regulator molecule. Prog Neurobiol. 2011;93:350-384.

41. Cardinali DP, Lynch HJ, Wurtman RJ. Binding of melatonin to human and rat plasma proteins. Endocrinology. 1972;91:1213-1218.

42. Claustrat B, Brun J, Chazot G. The basic physiology and pathophysiology of melatonin. Sleep Med Rev. 2005;9:11-24.

43. Tetsuo M, Markey SP, Kopin IJ. Measurement of 6-hydroxymelatonin in human urine and its diurnal variations. Life Sci. 1980;27:105-109.

44. Ma X, Idle JR, Krausz KW, Gonzalez FJ. Metabolism of melatonin by human cytochromes p450. Drug Metab Dispos. 2005;33:489-494.

45. Ferry G, Ubeaud C, Lambert PH, et al. Molecular evidence that melatonin is enzymatically oxidized in a different manner than tryptophan: investigations with both indoleamine 2,3-dioxygenase and myeloperoxidase. Biochem J. 2005;388:205-215.
46. Cardinali DP, Vacas MI, Boyer EE. Specific binding of melatonin in bovine brain. Endocrinology. 1979;105:437-441.

47. Niles LP, Wong YW, Mishra RK, Brown GM. Melatonin receptors in brain. Eur J Pharmacol. 1979;55:219-220.

48. Morgan PJ, Barrett P, Howell HE, Helliwell R. Melatonin receptors: localization, molecular pharmacology and physiological significance. Neurochem Int. 1994;24:101-146.

49. Reppert SM, Weaver DR, Ebisawa T. Cloning and characterization of a mammalian melatonin receptor that mediates reproductive and circadian responses. Neuron. 1994;13:1177-1185.

50. Reppert SM, Godson C, Mahle CD, Weaver DR, Slaugenhaupt SA, Gusella JF. Molecular characterization of a second melatonin receptor expressed in human retina and brain: the Mel1b melatonin receptor. Proc Natl Acad Sci US A. 1995;92:8734-8738.

51. Dubocovich ML, Delagrange P, Krause DN, Sugden D, Cardinali DP, Olcese J. International Union of Basic and Clinical Pharmacology. LXXV. Nomenclature, classification, and pharmacology of G proteincoupled melatonin receptors. Pharmacol Rev. 2010;62:343-380.

52. Pandi-Perumal SR, Trakht I, Srinivasan V, et al. Physiological effects of melatonin: role of melatonin receptors and signal transduction pathways. Prog Neurobiol. 2008;185:335-353.

53. Weaver DR, Reppert SM. The Mella melatonin receptor gene is expressed in human suprachiasmatic nuclei. Neuroreport. 1996;8:109-112.

54. Wu YH, Zhou JN, Van Heerikhuize J, Jockers R, Swaab DF. Decreased MT1 melatonin receptor expression in the suprachiasmatic nucleus in aging and Alzheimer's disease. Neurobiol Aging. 2007;28:1239-1247.

55. Liu C, Weaver DR, Jin X, et al. Molecular dissection of two distinct actions of melatonin on the suprachiasmatic circadian clock. Neuron. 1997;19:91-102.

56. von Gall C, Stehle JH, Weaver DR. Mammalian melatonin receptors: molecular biology and signal transduction. Cell Tissue Res. 2002;309:151-162.

57. Lewy AJ, Ahmed S, Jackson JM, Sack RL. Melatonin shifts human circadian rhythms according to a phase-response curve. Chronobiol Int. 1992;9:380-392.

58. Burgess HJ, Revell VL, Eastman CI. A three pulse phase response curve to three milligrams of melatonin in humans. J Physiol. 2008;586:639-647.

59. Weaver DR, Liu C, Reppert SM. Nature's knockout: the Mel1b receptor is not necessary for reproductive and circadian responses to melatonin in Siberian hamsters. Mol Endocrinol. 1996;10:1478-1487.

60. Masana MI, Sumaya IC, Becker-Andre M, Dubocovich ML. Behavioral characterization and modulation of circadian rhythms by light and melatonin in $\mathrm{C} 3 \mathrm{H} / \mathrm{HeN}$ mice homozygous for the RORbeta knockout. Am J Physiol Regul Integr Comp Physiol. 2007;292:R2357-R2367.

61. Saper CB, Fuller PM, Pedersen NP, Lu J, Scammell TE. Sleep state switching. Neuron. 2010;68:1023-1042.

62. Jan JE, Reiter RJ, Wasdell MB, Bax M. The role of the thalamus in sleep, pineal melatonin production, and circadian rhythm sleep disorders. J Pineal Res. 2009;46:1-7.

63. Golombek DA, Escolar E, Burin LJ, Brito Sanchez MG, Fernandez DD, Cardinali DP. Chronopharmacology of melatonin: inhibition by benzodiazepine antagonism. Chronobiol Int. 1992;9:124-131.

64. Golombek DA, Fernandez DD, Brito Sanchez MG, Burin L, Cardinali DP. Time-dependent anticonvulsant activity of melatonin in hamsters. Eur J Pharmacol. 1992;210:253-258.

65. Golombek DA, Pevet P, Cardinali DP. Melatonin effects on behavior: possible mediation by the central GABAergic system. Neurosci Biobehav Rev. 1996;20:403-412.

66. Munoz-Hoyos A, Sanchez-Forte M, Molina-Carballo A, et al. Melatonin's role as an anticonvulsant and neuronal protector: experimental and clinical evidence. J Child Neurol. 1998;13:501-509.

67. Molina-Carballo A, Munoz-Hoyos A, Sanchez-Forte M, UberosFernandez J, Moreno-Madrid F, Acuña-Castroviejo D. Melatonin increases following convulsive seizures may be related to its anticonvulsant properties at physiological concentrations. Neuropediatrics. 2007;38:122-125. 
68. Solmaz I, Gurkanlar D, Gokcil Z, Goksoy C, Ozkan M, Erdogan E. Antiepileptic activity of melatonin in guinea pigs with pentylenetetrazolinduced seizures. Neurol Res. 2009;31:989-995.

69. Cardinali DP, Pandi-Perumal SR, Niles LP. Melatonin and its receptors: biological function in circadian sleep-wake regulation. In: Monti JM, Pandi-Perumal SR, Sinton CM, editors. Neurochemistry of Sleep and Wakefulness. Cambridge, UK: Cambridge University Press; 2008.

70. Fenoglio-Simeone K, Mazarati A, Sefidvash-Hockley S, et al. Anticonvulsant effects of the selective melatonin receptor agonist ramelteon. Epilepsy Behav. 2009;16:52-57.

71. Golombek DA, Martini M, Cardinali DP. Melatonin as an anxiolytic in rats: time dependence and interaction with the central GABAergic system. Eur J Pharmacol. 1993;237:231-236.

72. Golombek DA, Escolar E, Burin LJ, Brito Sanchez MG, Cardinali DP. Time-dependent melatonin analgesia in mice: inhibition by opiate or benzodiazepine antagonism. Eur J Pharmacol. 1991;194:25-30.

73. Golombek DA, Escolar E, Cardinali DP. Melatonin-induced depression of locomotor activity in hamsters: time dependency and inhibition by the central type benzodiazepine antagonist Ro 15-1788. Physiol Behav. 1991;49:1091-1098.

74. Pang CS, Tsang SF, Yang JC. Effects of melatonin, morphine and diazepam on formalin-induced nociception in mice. Life Sci. 2001;68:943-951

75. Papp M, Litwa E, Gruca P, Mocaer E. Anxiolytic-like activity of agomelatine and melatonin in three animal models of anxiety. Behav Pharmacol. 2006;17:9-18.

76. Ulugol A, Dokmeci D, Guray G, Sapolyo N, Ozyigit F, Tamer M. Antihyperalgesic, but not antiallodynic, effect of melatonin in nerveinjured neuropathic mice: possible involvements of the L-arginine-NO pathway and opioid system. Life Sci. 2006;78:1592-1597.

77. Srinivasan V, Pandi-Perumal SR, Spence DW, et al. Potential use of melatonergic drugs in analgesia: mechanisms of action. Brain Res Bull. 2010;81:362-371.

78. Garfinkel D, Laudon M, Nof D, Zisapel N. Improvement of sleep quality in elderly people by controlled-release melatonin. Lancet. 1995;346:541-544.

79. Garfinkel D, Laudon M, Zisapel N. Improvement of sleep quality by controlled-release melatonin in benzodiazepine-treated elderly insomniacs. Arch Gerontol Geriatr. 1997;24:223-231.

80. Fainstein I, Bonetto A, Brusco LI, Cardinali DP. Effects of melatonin in elderly patients with sleep disturbance. A pilot study. Curr Ther Res. 1997;58:990-1000.

81. Dagan Y, Zisapel N, Nof D, Laudon M, Atsmon J. Rapid reversal of tolerance to benzodiazepine hypnotics by treatment with oral melatonin: a case report. Eur Neuropsychopharmacol. 1997;7:157-160.

82. Garfinkel D, Zisapel N, Wainstein J, Laudon M. Facilitation of benzodiazepine discontinuation by melatonin: a new clinical approach. Arch Intern Med. 1999;159:2456-2460.

83. Siegrist C, Benedetti C, Orlando A, et al. Lack of changes in serum prolactin, $\mathrm{FSH}, \mathrm{TSH}$, and estradiol after melatonin treatment in doses that improve sleep and reduce benzodiazepine consumption in sleepdisturbed, middle-aged, and elderly patients. J Pineal Res. 2001;30: 34-42.

84. Vissers FH, Knipschild PG, Crebolder HF. Is melatonin helpful in stopping the long-term use of hypnotics? A discontinuation trial. Pharm World Sci. 2007;29:641-646.

85. Cardinali DP, Gvozdenovich E, Kaplan MR, et al. A double blind-placebo controlled study on melatonin efficacy to reduce anxiolytic benzodiazepine use in the elderly. Neuro Endocrinol Lett. 2002;23:55-60.

86. Kunz D, Bineau S, Maman K, Milea D, Toumi M. Benzodiazepine discontinuation with prolonged-release melatonin: hints from a German longitudinal prescription database. Expert Opin Pharmacother. 2012;13:9-16.

87. Lemoine P, Nir T, Laudon M, Zisapel N. Prolonged-release melatonin improves sleep quality and morning alertness in insomnia patients aged 55 years and older and has no withdrawal effects. J Sleep Res. 2007; $16: 372-380$
88. Wade AG, Ford I, Crawford G, et al. Efficacy of prolonged release melatonin in insomnia patients aged 55-80 years: quality of sleep and next-day alertness outcomes. Curr Med Res Opin. 2007;23: 2597-2605.

89. Wade AG, Ford I, Crawford G, et al. Nightly treatment of primary insomnia with prolonged release melatonin for 6 months: a randomized placebo controlled trial on age and endogenous melatonin as predictors of efficacy and safety. BMC Med. 2010;8:51.

90. Lemoine P, Garfinkel D, Laudon M, Nir T, Zisapel N. Prolongedrelease melatonin for insomnia - an open-label long-term study of efficacy, safety, and withdrawal. Ther Clin Risk Manag. 2011;7: 301-311.

91. Luthringer R, Muzet M, Zisapel N, Staner L. The effect of prolongedrelease melatonin on sleep measures and psychomotor performance in elderly patients with insomnia. Int Clin Psychopharmacol. 2009;24:239-249.

92. Garfinkel D, Zorin M, Wainstein J, Matas Z, Laudon M, Zisapel N. Efficacy and safety of prolonged-release melatonin in insomnia patients with diabetes: a randomized, double-blind, crossover study. Diabetes Metab Syndr Obes. 2011;4:307-313.

93. Cardinali DP, Cano P, Jimenez-Ortega V, Esquifino AI. Melatonin and the metabolic syndrome. Physiopathologic and therapeutical implications. Neuroendocrinology. 2011;93:133-142.

94. Tutuncu NB, Batur MK, Yildirir A, et al. Melatonin levels decrease in type 2 diabetic patients with cardiac autonomic neuropathy. J Pineal Res. 2005;39:43-49.

95. Peschke E, Stumpf I, Bazwinsky I, Litvak L, Dralle H, Muhlbauer E. Melatonin and type 2 diabetes - a possible link? J Pineal Res. 2007;42:350-358.

96. Prokopenko I, Langenberg C, Florez JC, et al. Variants in MTNR1B influence fasting glucose levels. Nat Genet. 2009;41:77-81.

97. Sakotnik A, Liebmann PM, Stoschitzky K, et al. Decreased melatonin synthesis in patients with coronary artery disease. Eur Heart J. 1999;20:1314-1317.

98. Yaprak M, Altun A, Vardar A, Aktoz M, Ciftci S, Ozbay G. Decreased nocturnal synthesis of melatonin in patients with coronary artery disease. Int J Cardiol. 2003;89:103-107.

99. Girotti L, Lago M, Ianovsky O, et al. Low urinary 6-sulphatoxymelatonin levels in patients with coronary artery disease. J Pineal Res. 2000;29:138-142.

100. Dominguez-Rodriguez A, Abreu-Gonzalez P, Garcia MJ, Sanchez J, Marrero F, Armas-Trujillo D. Decreased nocturnal melatonin levels during acute myocardial infarction. J Pineal Res. 2002;33: 248-252.

101. Scheer FA, Van Montfrans GA, Van Someren EJ, Mairuhu G, Buijs RM. Daily nighttime melatonin reduces blood pressure in male patients with essential hypertension. Hypertension. 2004;43:192-197.

102. Cagnacci A, Cannoletta M, Renzi A, Baldassari F, Arangino S, Volpe A. Prolonged melatonin administration decreases nocturnal blood pressure in women. Am J Hypertens. 2005;18:1614-1618.

103. Grossman E, Laudon M, Yalcin R, et al. Melatonin reduces night blood pressure in patients with nocturnal hypertension. Am J Med. 2006;119:898-902.

104. Cavallo A, Daniels SR, Dolan LM, Bean JA, Khoury JC. Blood pressure-lowering effect of melatonin in type 1 diabetes. J Pineal Res. 2004;36:262-266.

105. Tamura H, Nakamura Y, Narimatsu A, et al. Melatonin treatment in peri- and postmenopausal women elevates serum high-density lipoprotein cholesterol levels without influencing total cholesterol levels. J Pineal Res. 2008;45:101-105.

106. Kozirog M, Poliwczak AR, Duchnowicz P, Koter-Michalak M, Sikora J, Broncel M. Melatonin treatment improves blood pressure, lipid profile, and parameters of oxidative stress in patients with metabolic syndrome. J Pineal Res. 2011;50:261-266.

107. Dolev Z. Case series of perimenopausal women with insomnia treated with mirtazapine followed by prolonged-release melatonin add-on and monotherapy. Arch Womens Ment Health. 2011;14:269-273. 
108. Otmani S, Demazieres A, Staner C, et al. Effects of prolonged-release melatonin, zolpidem, and their combination on psychomotor functions, memory recall, and driving skills in healthy middle aged and elderly volunteers. Hum Psychopharmacol. 2008;23:693-705.

109. Otmani S, Metzger D, Guichard N, et al. Effects of prolonged-release melatonin and zolpidem on postural stability in older adults. Hum Psychopharmacol. 2012;27:270-276.

110. Neri B, de Leonardis V, Gemelli MT, et al. Melatonin as biological response modifier in cancer patients. Anticancer Res. 1998;18: 1329-1332.

111. Weishaupt JH, Bartels C, Polking E, et al. Reduced oxidative damage in ALS by high-dose enteral melatonin treatment. J Pineal Res. 2006;41:313-323.

112. Chahbouni M, Escames G, Venegas C, et al. Melatonin treatment normalizes plasma pro-inflammatory cytokines and nitrosative/oxidative stress in patients suffering from Duchenne muscular dystrophy. J Pineal Res. 2010;48:282-289.

113. Waldhauser F, Waldhauser M, Lieberman HR, Deng MH, Lynch HJ, Wurtman RJ. Bioavailability of oral melatonin in humans. Neuroendocrinology. 1984;39:307-313.

114. Voordouw BC, Euser R, Verdonk RE, et al. Melatonin and melatoninprogestin combinations alter pituitary-ovarian function in women and can inhibit ovulation. J Clin Endocrinol Metab. 1992;74:108-117.
115. Nickkholgh A, Schneider H, Sobirey M, et al. The use of high-dose melatonin in liver resection is safe: first clinical experience. J Pineal Res. 2011;50:381-388.

116. Jou MJ, Peng TI, Hsu LF, et al. Visualization of melatonin's multiple mitochondrial levels of protection against mitochondrial $\mathrm{Ca} 2+-$ mediated permeability transition and beyond in rat brain astrocytes. J Pineal Res. 2010;48:20-38.

117. Jou MJ. Melatonin preserves the transient mitochondrial permeability transition for protection during mitochondrial Ca2+stress in astrocyte. J Pineal Res. 2011;50:427-435.

118. Peng TI, Hsiao CW, Reiter RJ, Tanaka M, Lai YK, Jou MJ. mtDNA T8993G mutation-induced mitochondrial complex V inhibition augments cardiolipin-dependent alterations in mitochondrial dynamics during oxidative, $\mathrm{Ca} 2+$, and lipid insults in NARP cybrids: a potential therapeutic target for melatonin. J Pineal Res. 2012;52:93-106.

119. Solomon DA, Leon AC, Endicott J, et al. Psychosocial impairment and recurrence of major depression. Compr Psychiatry. 2004;45:423-430.

120. Pandi-Perumal SR, Bahammam AS, Brown GM, et al. Melatonin antioxidative defense: therapeutic implications for aging and neurodegenerative processes. Neurotoxicity Res. June 28, 2012. [Epub ahead of print.]
ChronoPhysiology and Therapy

\section{Publish your work in this journal}

ChronoPhysiology and Therapy is an international, peer-reviewed, open access journal focusing on research into the cyclic variations and rhythmicity in physiological processes in the body and the research and development and optimal timing of administration of therapeutic targets to achieve improved outcomes and quality of life for the patient. The

\section{Dovepress}

manuscript management system is completely online and includes a very quick and fair peer-review system. Visit http://www.dovepress.com/ testimonials.php to read real quotes from published authors. 